\title{
FERRAZ, Eucanaã. Rua do mundo. São Paulo: Companbia das Letras, 2004.
}

Bernardo Nascimento de Amorim I UFMG

Falar sobre a atual poesia brasileira não é tarefa das mais fáceis. A quantidade de autores a publicarem seus livros, por pequenas e grandes editoras, apresenta um desafio ao leitor e ao crítico que procuram acompanhar de perto a produção recente. Além de ser difícil ter uma visão de conjunto sobre esta produção, que permitisse o delineamento de algumas de suas tendências gerais, é igualmente difícil separar, como se diz, o joio do trigo, em uma época na qual a miríade de referências torna problemático o estabelecimento de critérios mais ou menos confiáveis de qualidade.

Eucanaã Ferraz, poeta nascido no Rio de Janeiro, em 1964, e professor de literatura brasileira na UFRJ, chega ao seu quarto livro, Rua do mundo, tendo alcançado um lugar relativamente confortável no sistema literário nacional. Além de ser professor de uma Universidade Federal, o que confere a ele certa autoridade, em 2002, o autor recebeu o prêmio Alphonsus de Guimaraens, da Fundação Biblioteca Nacional, pelo volume Desassombro. Em 2004, publica o seu último livro, por uma editora já há um bom tempo consolidada no mercado, a prestigiosa Companhia das Letras. Sabe-se que, no Brasil, o respaldo do mercado editorial e da crítica especializada muitas vezes é apenas o fruto das boas relações de um autor, o que chega a ser suficiente 
para a projeção de uma obra. Contudo, este não parece ser o caso de Eucanaã, cujo trabalho tende a ganhar em valor quanto mais acuradamente dele se aproximam os leitores.

Pode-se começar a falar de Rua do mundo notando duas de suas marcas mais evidentes, procedimentos repetidos ao longo de todo o livro. A primeira viria a ser o fato de a maior parte dos títulos dos poemas estarem dispostos após as composições, e não antes, como é de praxe. Isso acontece em todos os poemas de uma página, sendo que, nos outros, maiores, o título não vem após o texto completo, mas ao final de sua primeira página. Tal recurso faria presente, mais do que simplesmente um desvio em relação à norma, a concepção de que o título, embora possa ter algum caráter de síntese do que diz o poema, não comporta uma significação que seja a origem da composição, a sua idéia motriz, a presidir todo o processo de escrita e de leitura. No canto inferior da página, tem-se, em negrito, uma expressão, um nome próprio, uma palavra, que mais acrescentam um elemento ao texto do que encerram o seu sentido.

A segunda marca a ser ressaltada relaciona-se à estrofação dos poemas, cada um deles escrito em estrofes regulares, predominantemente dísticos, tercetos e quartetos, em meio dos quais aparece um quinteto e um poema em sextilhas. A regularidade poderia ser tomada como o sinal de uma vontade de ordenação do mundo, das idéias, dos sentidos, vontade que permanece, que insiste, mesmo diante da consciência de que toda ordenação é frágil. Nos poemas, de fato, embora se busque a ordem, a regularidade, elas se apresentam marcadas por ruídos, seja na própria fragmentação dos versos, que desarticulam a unidade de ritmo e sentido, seja na falta de propriedade sintática, que representaria a falha em um sistema de ordenação. Em Carícia, do qual transcrevo o último verso da primeira estrofe e a segunda, tem-se um bom exemplo desta quebra da ordem: "voltar. Repita, // demorando-se mais, / de modo que a mão descanse / naquele rosto, como se, / e se esqueça de que.” (p. 91). Na ausência do complemento das orações, seriam encenadas as limitações do discurso, a incapacidade de a língua ser capaz de dizer de maneira plena o que se quer dizer. Ter-se-ia, então, uma dinâmica dialética, uma vez que se busca a ordenação, mas sabendo-se de sua precariedade. O poeta encontra-se, a um só tempo, guiado por um desejo de ordem e pelo impulso de procurar uma via de ruptura, que lhe permitisse ir além dos limites constitutivos da matéria prima de seu fazer. 
O poema Carícia tem como temática a relação amorosa em sentido amplo, a troca de afeto, que vem a ser um dos temas de destaque do livro de Eucanaã. De modo significativo, em outro dos poemas em que aparece o assunto, Preciso, vê-se a iminência da irrupção da desordem, como se isto fosse uma ameaça constante:

\section{(...)}

Meu esforço para que a voz se mova na fibra exata, para que a cidade, cada dedo de sua álgebra, não desabe, para que fábulas, riso e palavras

estejam no ponto certo, assim como as pedras, prédios e montanhas que mantenho quietos a custo. (...)(p. 73)

O desejo de alcançar a precisão tende a manifestar-se como experiência de vida, de modo geral, e como desejo do poeta ao lidar com o seu próprio fazer, de modo particular, estando as duas coisas interligadas. Efetivamente, o amor, como tema, e a discussão sobre a palavra, a poesia, são elementos constantes no livro, configurando-se como núcleos das vivências de um sujeito. No poema O equilibrista, vê-se a luta do poeta em busca da forma para as idéias: "Traz consigo resguardada / certa idéia que lhe soa / clara, exata. // No entanto, hesita: que palavra / a mais bem medida e cortada / para dizê-la?" (p. 47). Em Caça, nota-se uma afirmação lúcida sobre o trabalho do poeta, que tem que lidar com as astúcias da palavra: "Pois a palavra mais desejada / é aquela que salta / por sobre a página clara, muito acima / da tocaia calma que lhe estendemos a custo.” (p. 43). Ainda com relação à temática do amor, vale a pena transcrever todo o poema Graça, talvez um dos mais belos do livro, em que o direcionamento do discurso a um interlocutor serve bem à manifestação de afetos:

Não saberia dizer a hora em que me desfizera de tudo o que não era teu, 
quando cada coisa se deixou cobrir

por tua presença sem margens

e deixou de haver um lado

que fosse fora de ti. (p. 67)

Em Rua do mundo, não são todos os poemas em que há essa manifestação claramente afetiva do sujeito. Muitas vezes, a poesia ganha um certo caráter descritivo, originando-se do ato do poeta de se deter diante de algo construído pelo homem, como os edifícios da cidade grande, a igreja modernista projetada por Le Corbusier em Ronchamp, na França, as roupas de estilistas como Issey Miyake e Rei Kawacubo, os parangolés de Hélio Oiticica. As descrições, regidas por um princípio metafórico, levarão à abertura para a criação de imagens, de analogias. Em especial, neste ponto, mereceria destaque a curiosa associação feita pelo poeta entre a vestimenta desenhada por estilistas e a casa, como se as roupas fossem casas de se vestir. Cria-se uma fértil associação entre o trabalho do fashion designer e o do arquiteto. Em Issey Miyake, lê-se: "Vestir essa casa / será sempre desvestir-se do // um, será estar nu: varandas / tudo." (p. 29). Não é por acaso que o segundo poema do livro chama-se Vestir as cidades: "trajar-nos-á perfeita (é a ilusão que o diz) aquela / que só visitamos nas fotografias, no desejo, // nas vitrines, e que imaginamos impecável / nos ombros e nos punhos (...)" (p. 6). Na última composição, em que se fala dos parangolés, de Hélio Oiticica, retorna essa associação entre a casa e o que é fabricado para ser levado no corpo: "casa mais que nenhuma outra / casa, a mais inteira, // sem porta e sem tranca. / Casa antes da casa: / Parthenon, barraco." (p. 124).

Elemento recorrente no livro, a casa poderia vir a ser tomada como espaço de abrigo, de recolhimento, de isolamento do burburinho do mundo, este que, para muitos, não só poetas, acaba representando algo hostil. Os poemas de Eucanaã, entretanto, não parecem conceber uma separação entre os espaços de fora, da rua, do mundo, e os espaços de dentro, do eu, no qual porventura vicejasse algum tipo de ensimesmamento. A ausência de separação, neste caso, constitui-se como a afirmação do caráter positivo de uma permanente abertura para o contato, para a observação, para a experiência e, ainda, para o encantamento, resultante da transformação que o olhar do poeta efetua sobre o real, tornando-o palavra poética. A disposição para transfigurar o vivido e o observado, como modo de apropriação de si mesmo 
e do mundo, leva o sujeito dos poemas a deixar-se reger pelo impulso de nomear ou renomear as coisas, dar a elas um significado próprio, ressignificálas, a partir de sua inserção em uma lógica singular, subjetiva. Dado relevante, a falta de oposições bem delimitadas manifesta-se no modo como se dá a relação de transfiguração do mundo em poesia. Seria mesmo pertinente pensar que os poemas do livro evidenciam um processo de transformação do prosaico, mas sem que haja uma demarcação excludente de territórios, como se fora necessário, ao poético, recusar o prosaico para existir. Veja-se, a este respeito, alguns fragmentos de Presto:

\section{(...)}

Posso farejar o amarelo das amendoeiras

de então (amarelas como teu cabelo)

e a praia, os bares, a ferrugem, nossas costas

e braços liquefeitos. (...)

(...)

(...) Girassóis

em bando assestarão suas lâminas

em direção aos táxis

enquanto os rios, erráticos, desaguarão

à porta dos edifícios da Senador Vergueiro. (p. 9)

A poesia de Eucanaã, gestada a partir da experiência particular que o poeta tem com o que observa e vivencia, lançado no mundo, parece ter, efetivamente, no desejo de abertura e expansão a sua grande mola propulsora. Recusam-se delimitações rígidas, mesmo quando se revela a necessidade da ordenação, para que os espaços se misturem, se interpenetrem, como se penetram os parangolés de Oiticica. O universo que o poeta busca em sua criação é um mundo em que "as casas não têm paredes ou teto", em que "não há frentes de combate", em que as "linhas não são rumos ou normas", em que "se ganha o que se perde", como está dito no poema que abre o livro, intitulado Um mundo (p. 5). 
A valorização do contato, os afetos, os modos de lidar com as limitações da palavra e com o desejo de regularidade, a procura da expansão de sentidos, tudo isso tornado um universo poético, de forma coerente e bem arquitetada, faz de Eucanaã um autor que merece a atenção dos leitores de poesia interessados na recente produção nacional. Talvez, quando for possível considerar as realizações poéticas das últimas décadas como um conjunto, com disposições relativamente compartilhadas, seja desejável localizar melhor o Rua do mundo no contexto de sua época. Por ora, no entanto, basta a constatação, a que acredito poder-se chegar sem maiores hesitações, de que o livro e o poeta têm o seu valor. 